\title{
Portal hypertension complicating choledochal cyst
}

\begin{abstract}
Portal hypertension is a rare complication associated with choledochal cysts. Management issues of PH patients are inadequately addressed, as its incidence is low and underlying causes are variable. We report a child here in which concomitant excision of choledochal cyst, hepaticoenterostomy and portosystemic shunt however was successfully done.
\end{abstract}

Volume 8 Issue I - 2018

\author{
Yogesh Kumar Sarin, Nitin Jain \\ Department of Pediatric Surgery, Maulana Azad Medical College, \\ India
}

Correspondence: Yogesh Kumar Sarin, Director Professor \&
Head, Department of Pediatric Surgery, Maulana Azad Medical College, New Delhi-I I0002, India, Email yksarin@hotmail.com

Received: December 20, 2017 | Published: January 31, 2018

\section{Abbreviations: CC, choledochal cyst; $\mathrm{PH}$, portal hypertension Introduction \\ Choledochal cyst (CC) is an uncommon congenital biliary tract anomaly associated with pancreaticobiliary malunion (PBMU) and predominantly a disease of the younger age group. Choledochal cysts are associated with varieties of hepatobiliary pathology \& complications, with portal hypertension $(\mathrm{PH})$ reported as one of its rare complications. ${ }^{1-4}$}

Portal hypertension is a known complication of delayed presentation of choledochal cyst. The etiology of portal hypertension in these cases has not been well studied, but it may be related to compression of the cyst over the portal vein, secondary biliary cirrhosis, or even extra hepatic portal venous thrombosis.

In the literature, $\mathrm{CC}$ presenting with $\mathrm{PH}$ has not been addressed adequately and there is a paucity of literature on $\mathrm{CC}$ complicated by $\mathrm{PH}$. Gastrointestinal bleeding, splenomegaly or incidental discovery of esophageal varices led to the diagnosis of associated PH. Excision of $\mathrm{CC}$ and bilio-enteric bypass may not be feasible in those patients as there is a formation of massive collaterals in the region of porta associated with secondary $\mathrm{PH}^{5,6}$ An initial approach of internal drainage (endoscopic/ operative) of the cyst may allow regression of collaterals and subsequent safe excision of the cyst in this difficult group of patients.

Review of the literature did not reveal a single case where the recommended CC excision and hepaticoenterostomy has been done along with portosystemic shunt surgery. We report this case to report an unusual variant of $\mathrm{CC}$ and to highlight the feasibility of singlestage surgical management of $\mathrm{CC}$ and associated $\mathrm{PH}$.

\section{Case report}

A 10-year-old malnourished boy weighing $20 \mathrm{~kg}$ presented with continuous, non-colicky, abdominal pain for 1 year and jaundice for 6-8 months. There was history of pruritis and few episodes of low grade fever. There was no associated vomiting, hemetemesis, or hematochezia. Examination revealed jaundice, anemia and hepatosplenomegaly; spleen was palpable $17 \mathrm{~cm}$ below the costal margin.

His hemoglobin, total leukocyte and platelet counts were $9.6 \mathrm{gm} \%, 2400 / \mathrm{mm} 3$, and $58000 / \mathrm{mm} 3$ respectively. The bilirubin levels were minimally raised (total $2 \mathrm{mg} / \mathrm{dl}$, and direct $1.6 \mathrm{mg} / \mathrm{dl}$ ), and the hepatic enzymes AST and ALT were raised to148.6 and 146.1 units/1 respectively (normal up to $40 \mathrm{U} / 1$ each). Rest of the liver function tests, renal function tests and prothrombin time were normal. Ultrasonography (US) confirmed hepatosplenomegaly and portal hypertension. The common bile duct was dilated up to $14 \mathrm{~mm}$ at porta hepatis and contained stones; intrahepatic biliary radicals were grossly dilated. Doppler US showed portal vein measuring $6 \mathrm{~mm}$ in diameter at porta hepatis and $10 \mathrm{~mm}$ proximally; it was patent for its entire course. The splenic vein was $11 \mathrm{~mm}$ wide at hilum; the left renal vein was $6.5 \mathrm{~mm}$ wide. There were many enlarged periportal and peripancreatic nodes. MRCP revealed gross splenomegaly; $12 \mathrm{~mm}$ wide $\mathrm{CC}$ with choledocholithiasis. Both the hepatic ducts were dilated (left $>$ right) with dilatation of Intrahepatic biliary radicals. There was a $12 \mathrm{~mm}$ wide tubular structure seen arising from the right side of the lower $1 / 3 \mathrm{rd}$ of $\mathrm{CC}$ and running parallel to it. The distended gallbladder opened in this structure through a long cystic duct. Upper GI endoscopy revealed grade III esophageal varices. Liver biopsy done preoperatively was consistent with changes of obstructive pathology with marked fibrosis, suggestive of early cirrhosis.

In view of the gross splenomegaly and hypersplenism, it was decided to perform distal spleno-renal shunt along with definitive management of choledochal cyst. Intraoperatively, the liver was enlarged and nodular with sharp margins; the spleen was massively enlarged. There was fusiform dilatation of CBD, with a diverticulum appearing to originate from the lower $1 / 3$ rd of the CBD with the cystic duct draining into the right side of the diverticulum. Intraoperatively, The CC/diverticulum/gall bladder had multiple soft pigment stones. Total excision of the $\mathrm{CC} /$ diverticulum/gall bladder and hepaticoduodenostomy was done. Then, we proceeded to do distal splenorenal shunt. The period of left renal vein clamping was about 20 min. He was administered adequate blood and fresh frozen plasma intraoperatively and in immediate post-operative period (Figure 1).

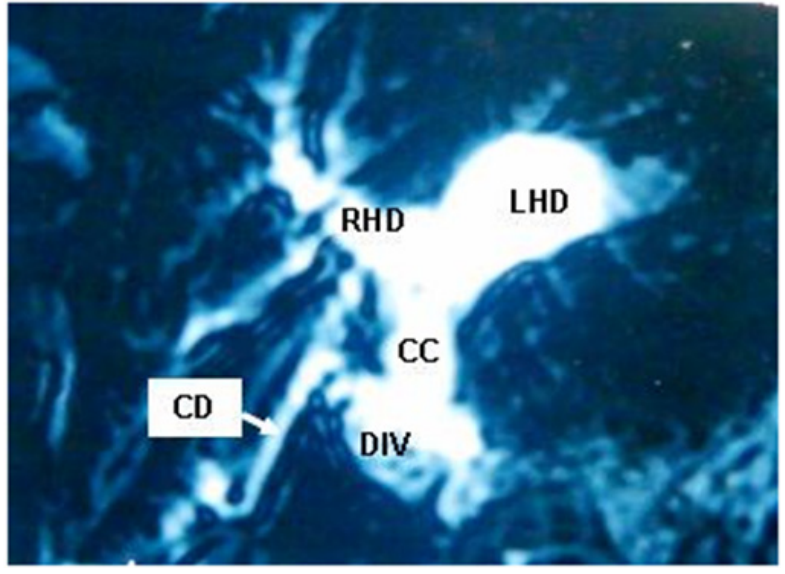

Figure I MRCP showing fusiform dilatation of $C B D$, dilated hepatic ducts PBMU, and a diverticulum arising from lower $1 / 3^{\text {rd }}$ of the CBD with the cystic duct draining into the right side of the diverticulum $(\mathrm{RHD}=$ right hepatic duct; $\mathrm{LHD}=$ left hepatic duct; $C C=$ type I choledochal cyst; $\mathrm{DIV}=$ diverticulum or type II choledochal cyst; $C D=$ cystic duct). 
It was decided to electively ventilate the child in view of the long duration of surgery and significant intra-abdominal blood loss. He required inotropic support for the first 4 postoperative days. He was started on anticoagulants on 1 st operative day. He was extubated on 5th postoperative day, by which time his spleen had considerably receded and leukocyte count and platelets had normalized. Histopathology confirmed the diagnosis of CC; the liver biopsy showed maintained hepatic architecture with mild lymphocytic infiltrate with mild to moderate periportal fibrosis.

He has been doing well on seven-year follow up and the spleen is shrunk remarkably.

\section{Discussion}

Choledochal cyst (CC), a congenital malformation of the biliary tract and can have a varied presentation. Choledochal cyst is a surgical problem typically related to infancy and childhood. Portal hypertension, in cases of $\mathrm{CC}$, may develop by various mechanisms. The most important mechanism which has been proposed in children is the direct compression of the portal vein by the $\mathrm{CC}$ by virtue of its location anterior to the portal vein and pressure on the vein by the sheer weight of cyst. Other mechanisms which have been described include biliary obstruction leading to secondary biliary cirrhosis and portal vein thrombosis resulting from recurrent cholangitis. ${ }^{1,5,7}$ The mechanism responsible for development of $\mathrm{PH}$ determines whether surgical Intervention may be beneficial. Direct compression of the portal vein is reported as the main mechanism in children. Surgical decompression of the cyst by internal drainage has been shown to reverse PT in these patients. ${ }^{6,8}$

The important issue worth discussion in this case, is the presence of $\mathrm{PH}$ and hypersplenism and its successful management by simultaneous portosystemic shunt. Review of the literature did not reveal a single case where the recommended $\mathrm{CC}$ excision and hepaticoenterostomy has been done along with portosystemic shunt surgery. The presence of portal hypertension in a child with choledochal cyst complicates the management. The presence of vascular collaterals in the region of porta can make attempt at excision of the cyst a challenging and lifethreatening experience.

Choledochal cyst excision and bilioenteric bypass has been recommended and practiced as the standard surgical treatment for choledochal cyst to avoid complications and prevent malignancy. The ideal treatment for choledochal cyst may not be feasible in children with associated portal hypertension due to the presence of collaterals in the region of porta. An initial approach of internal drainage (endoscopic/operative) of the cyst has been performed to allow regression of collaterals and subsequent safe excision of the cyst in this difficult group of patients. ${ }^{8-10}$ In the presence of extensive collaterals in the hepatoduodenal ligament, portal decompression in the form of portosystemic shunt has been recommended to be done as a first step, followed by cyst excision few weeks later.

The recommended surgical treatment for symptomatic hypersplenism in setting of Intrahepatic cause of $\mathrm{PH}$ for patients with preserved LFTs, such as seen in the present case, is some type of portal flow preserving technique such as selective distal splenorenal shunt and splenectomy. ${ }^{9-11}$ However, spleen preserving shunts are preferred in children to reduce the risk of post-splenectomy sepsis and they have been known to result in long-times patency and cessation of preoperative symptoms. ${ }^{12}$ Some authors have advocated distal splenorenal shunts with partial splenic resection instead, ${ }^{13}$ others have favoured partial splenic embolization. ${ }^{14}$

In the present case, presence of hypersplenism concurrently with $\mathrm{PH}$ made us to the decision in favour of concomitant portosystemic shunt and it worked well for the patient.

\section{Contribution of the authors}

YKS managed the patient, drafted the manuscript, approved the final version and $\mathrm{NJ}$ added useful inputs in the manuscript.

\section{Conflicts of interest}

None.

\section{Funding}

None.

\section{References}

1. Nagorney DM, Mdlrath DC, Adson MA. Choledochal Cyst inadults: clinical management. Surgery. 1984;96(4):656-663.

2. Gigot J, Nagorney DM, Farnell M, et al. Bile ductcysts: a changing spectrum of disease. J Hepatobiliary Pancreat Surg. 1996;3(4):405-411.

3. Lenriot JP, Gigot JF, Segol P, et al. Bile duct cysts in adults: a multiinstitutional retrospective study. French Associations of Surgical Research. Ann Surg. 1998;228(2):159-166.

4. Lipsett PA, Pitt HA, Colombani PM, et al. Choledochal cyst disease. A changing pattern of presentation. Ann Surg. 1994;220(5):644-652.

5. Martin LW, Rowe GA. Portal hypertension secondary to choledochal cyst. Ann Surg. 1979; 190(5):638-639.

6. Rao KL, Chowdhary SK, Kumar D. Choledochal cyst associated with portal hypertension. Pediatr Surg Int. 2003;19(11):729-732.

7. Agarwal N, Kumar S, Hai A, et al. Mixed type I and II choledochal cyst in an adult. Hepatobiliary. Pancreat Dis Int. 2009;8(4):434-436.

8. Lal R, Agarwal S, Shivhare R, et al. Management of complicated choledochal cysts. Dig Surg. 2007; 24(6): 456-462.

9. Hase R, Hirano S, Kondo S, et al. Long-term efficacy of distal splenorenal shunt with splenopancreatic and gastric disconnection for esophagogastric varices in patients with idiopathic portal hypertension. World J Surg. 2005;29(8):1034-1036.

10. Saluja SS, Mishra PK, Sharma BC, et al. Management of choledochal cyst with portal hypertension. Singapore Med J. 2011;52(12):e239-e243.

11. Robberecht E, Van Biervliet S, Vanrentergem K, et al. Outcome of total splenectomy with portosystemic shunt for massive splenomegaly and variceal bleeding in cystic fibrosis. JPediatr Surg. 2006;41(9):1561-1565.

12. Lillegard JB, Hanna AM, McKenzie TJ, et al. A single-institution review of portosystemic shunts in children: an ongoing discussion. HPB Surg. 2010;2010:964597.

13. Gajin P, Radević B, Nenezić D, et al. [Distal splenorenal shunt with partial spleen resection]. Srp Arh Celok Lek. 2007;135:293-297. [Article in Serbian]

14. Koconis KG, Singh H, Soares G. Partial splenic embolization in the treatment of patients with portal hypertension: a review of the English language literature. J Vasc Interv Radiol. 2007; 18(4):463-481. 